\title{
W.O.J. NIEUWENKAMP EN ZIJN VORSTELIJKE LEEUWENDOOSJE
}

Afgelopen winter waren er in de Nieuwe Kerk in Amsterdam tijdens de tentoonstelling 'Indonesia: de ontdekking van het verleden' vele paleisschatten te zien die afkomstig waren uit Zuid-Bali. Zij waren buitgemaakt tijdens militaire expedities, bijvoorbeeld tegen het rijkje Klungkung in 1908, of verzameld door liefhebbers van Balinese kunst en kunstnijverheid, zoals de schilder W.O.J. Nieuwenkamp (1874-1950). Alle voorwerpen op deze tentoonstelling behoorden tot de collecties van het Museum Nasional Indonesia in Jakarta en het Rijksmuseum voor Volkenkunde in Leiden. Echter, ook de afdeling Aziatische Kunst van het Rijksmuseum beheert een prachtig voorwerp dat in een dergelijke expositie niet zou misstaan. Het behoort tot het langdurig bruikleen van de Vereniging van Vrienden der Aziatische Kunst en is een ivoren doosje, verzameld door W.O.J. Nieuwenkamp, en vermoedelijk afkomstig uit het paleis in Klungkung, Zuid-Bali. De doos is gemaakt van één stuk uitgehold ivoor, en prachtig bewerkt in de vorm van een gevleugelde leeuw (afb. 1). ${ }^{1}$ In de lange manen die over de rug van de leeuw liggen is een kleine vierkante deksel uitgesneden. De hoogte van het dier is 11 centimeter en de lengte 17; het lage voetstuk is van beschilderd hout. Het dateert vermoedelijk uit de $19^{e}$ eeuw.

In dit artikel wil ik zowel ingaan op de verzamelgeschiedenis van het doosje, als op de functie en de betekenis ervan. Van wie was het doosje, hoe is het in de collectie Aziatische Kunst van het Rijksmuseum gekomen, waarvoor werd het gebruikt, wat betekent het leeuwtje en in hoeverre is het doosje vergelijkbaar met hedendaagse vormen van rituele kunst op Bali? ${ }^{2}$

\section{Kunstverzamelaar W.O.J. Nieuwenkamp}

In 1925 reisde de bekende 'artistieke duizendpoot' Wijnand Otto Jan Nieuwenkamp naar Bali. Het was inmiddels zijn vierde reis naar dit Indonesische eiland, waar hij in 1904 voor het eerst mee had kennis gemaakt en waar hij bijzonder van was gaan houden. Als veelzijdig kunstenaar had hij als geen ander oog voor de grote rijkdom aan culturele uitingen op Bali, en hij herkende het vakmanschap waarmee veel voorwerpen waren gemaakt. Al tijdens zijn eerste reis was hij begonnen met verzamelen, voor zijn eigen privécollectie, maar ook in opdracht van musea. In het voorwoord van het door Nieuwenkamp in eigen beheer en met eigen illustraties uitgegeven boek Bali en Lombok laat de kenner van Indonesische kunst en kunstnijverheid bij uitstek, G.P. Rouffaer, zich in lyrische bewoordingen uit over zowel de kwaliteit van de door Nieuwenkamp verzamelde voorwerpen als zijn eigen kunst. ${ }^{3}$

Net als tijdens zijn vorige reizen schetste en tekende hij veelvuldig, verzamelde hij kunstvoorwerpen, en maakte hij uitvoerige aantekeningen in dagboeken die hij in reisverslagen en artikelen uitwerkte. Hieruit blijkt niet alleen date access 
Nieuwenkamp een grote belangstelling en bewondering had voor de kunst en cultuur van Bali, maar ook komen wij hierdoor meer te weten over de omstandigheden waaronder zijn collecties tot stand zijn gekomen.

Uit een nog niet gepubliceerd reisverslag van Nieuwenkamp, aan mij zeer vriendelijk ter beschikking gesteld door de Stichting Museum Nieuwenkamp te Edam, zijn de volgende citaten afkomstig. Op 6 juni 1925 was hij vanuit Noord-Bali in Klungkung in het zuiden aangekomen.

\section{'DAGJESMENSCHEN EN EEN RARITEITENMARKT}

De pasanggrahan zit vol dagjesmenschen, touristen van de K.P.M. die de lunch hier gebruiken en op het voorplein zitten talrijke kooplieden met groote uitstallingen, op den grond uitgespreid, van allerhande snuisterijen, meest nieuwe spullen, apart voor vreemdelingen vervaardigd. Om drie uur vertrekken de touristen, in vele auto's; ook de kooplui verdwijnen van het toneel. Ik blijf alleen als gast van de pasanggrahan achter [...] Het ligt naast de resten van de gesloopte poeri van den laatsten Dewa Agoeng, tegenover het controleurserf.

\section{MIJN VERZAMELING NEEMT TOE IN OMVANG [...]}

Het duurt niet lang of het voorplein ligt weer vol met weefsels, vlechtwerk, snijwerk, koper- en zilverwerk, krissen en van alles en nog wat; meest nieuwe spullen, voor touristen vervaardigd. Doch touristen zijn er niet vandaag, en ik ben de eenige marktganger. Spoedig heb ik ontdekt dat er onder al dat nieuwe toch ook wel eenige aardige oudere Balische voonwerpen zijn te vinden. [...] Ik gevoel groote bewondering voor deze eenvoudige landbouwers die zulke knappe kunstenaars en handwerkers zijn.

[...]

\section{EEN PRACHTIGE OFFERDOOS VAN IVOOR}

De mooiste aanwinst is een kostbare ivoren offerdoos, in den vorm van een gevleugelde leeuw of singa, een uiterst zeldzaam stuk, zooals er weinig op Bali te vinden zullen zijn. Volgens overlevering bracht de vorst - Dewa Agoeng - van Kloengkoeng hierin zijn offerande, bestaande uit gouden munten, bij groote feestelijke gebeurtenissen naar den Poera Balé Agoeng.

\section{NOG MEER GEWICHTIGE AANKOPEN}

Het gerucht dat er nu een Blanda in de pasanggrahan woont, die van alles koopt, als het maar oud is, heeft zich snel in de dessa verspreid en vandaag is het, op ons voorpleintje, nog drukker dan gisteren met lieden, die hoopvol hun waren, voor zich, op het grint ten toon spreiden.'

Nieuwenkamp liet zich tot meer aankopen verleiden, maar hij kon met recht trots zijn op zijn 'mooiste aanwinst', inderdaad een zeldzaam stuk. Hij heeft het bijna tien jaar in zijn eigen collectie gehouden totdat hij het in november 1934 voor 300 gulden verkocht aan de Vereniging van Vrienden der Aziatische Kunst. In de tussenliggende periode had hij over het doosje gepubliceerd, ${ }^{4}$ en had het deel uitgemaakt van verschillende tentoonstellingen van Indonesische kunst. Samen met een vergelijkbare doos, 
maar dan geheel van hout, staat het ivoren doosje afgebeeld in het boek dat Nieuwenkamp schreef over zijn Florentijnse villa, die hij in 1926 kocht en waar hij vele kostbaarheden uit zijn collectie een plaats had gegeven. ${ }^{5}$

\section{Paleisschatten uit Klungkung}

De Balinese verkoper van het doosje vertelde aan Nieuwenkamp dat het vroeger was gebruikt door de voormalige vorst van Klungkung, de Dewa Agung. Specifieke bewijzen hiervoor ontbreken, maar gezien de kostbaarheid van het materiaal en het verfijnde vakmanschap van de ornamentiek is het heel goed mogelijk dat het ivoren doosje deel uitmaakte van de collectie van het paleis in Klungkung, voordat dit rijkje in april 1908 door de Nederlanders werd overmeesterd. Hierbij vonden de vorst en zijn familieleden in een dramatische zelfmoordaanval, puputan, de dood, en werd het paleis met de grond gelijk gemaakt. Hoewel Nieuwenkamp in die periode niet zelf op Bali was, gaf hij in 1909 deze gebeurtenissen weer in zijn boek Bali en Lombok: ${ }^{6}$ 'Een enkel woord nog over het einde van het eens zo machtige rijk van Kloenkoeng. [...] Kort na de invoering van de opiumregie op heel Bali, kwam Kloenkoeng in verzet. [...]1 7 April 1908. Onze macht was te gering (een twee honderd man slechts) om Kloenkoeng te kunnen aanvallen en trok op Lebih terug. Spoedig kwamen weer de oorlogschepen en vlogen de granaten weer met zwermen het land in. [...] Maar tot een gevecht zou het ook hier niet komen. 29 april werd met de inmiddels aangekomen versterkingen en nadat de hoofdplaats nog eens duchtig gebombardeerd was, naar Gelgel en daarna naar de poeri in de hoofdplaats opgerukt. En weer herhaalden zich de tragische gebeurtenissen van Den-Pasar en Pametjoetan; ook de Déwa Agoeng, begrijpende dat het voorgoed gedaan zou zijn met zijn heerschappij, was tot een poepoetan besloten. Hij en zijn getrouwen, vele vrouwen en kinderen lieten zich door onze kogels doorboren; ook zijn zoontje, waar ik indertijd kennis mede maakte, en de Tjokorda van Gelgel kwamen daarbij om. [...] De hoofdplaats werd zonder tegenweer bezet en daarmede had het rijk Kloenkoeng opgehouden te bestaan.'

$\mathrm{Na}$ de puputan werden ruim vijfhonderd kostbare voorwerpen buitgemaakt. Zij werden eerst ter plekke uitgezocht door assistent-resident H.J.E.F. Schwartz, en vervolgens opgestuurd naar Batavia, waar een speciale commissie van het Bataviaasch Genootschap van Kunsten en Wetenschappen werd belast met het over verschillende musea verdelen van de schatten. Het Rijksmuseum voor Volkenkunde in Leiden, dat aan het Gouvernement reeds te kennen had gegeven belangstelling te hebben voor een gedeelte van de kostbare voorwerpen, kreeg 133 objecten, het Museum van het Bataviaasch Genootschap behield er $157 .^{7}$

Onder de kostbaarheden bevonden zich ook voorwerpen die een functie hadden bij Balinese offerrituelen. Zo waren er gouden offerschalen, een zilveren wijwatervat en zilveren lampen die priesters gebruikten bij de uitvoering van hun ritueel. Een aantal beeldjes, gemaakt van Chinese munten, was volgens Schwartz, die in 1915 adjunct-conservator werd in het Museum van het Bataviaasch Genootschap, afkomstig uit de vorstelijke vooroudertempel die zich binnen de paleismuren bevond. Het is mogelijk dat het ivoren doosje, immers 'volgens overlevering' ook gebruikt bij offerrituelen, zich eveneens in de collectie tempelkostbaarheden bevond. 
Maar hoe is dit doosje aan de aandacht van Schwartz ontsnapt zodat het geen deel uitmaakte van de schatten die door de Nederlandse bestuurders naar Batavia werden gezonden? Zeker weten zullen we het nooit, maar het is goed mogelijk dat het doosje door een Baliër werd meegenomen uit het paleis voordat de Nederlandse troepen de puri (paleis) en de omgeving hiervan volledig onder controle hadden. Een correspondent van het blad De Locomotief schreef naar de redactie op 1 mei 1908: 'Toen ik den dag na de poepoetan het vorstenverblijf ging bezoeken, bood dit een treurigen aanblik van gevallen grootheid. [...] Overal in de poeri staan schildwachten om het rampassen te voorkomen, welke maatregel hoog noodig was.'

Dergelijk rampassen, plunderen, door de Balische bevolking, had Nieuwenkamp twee jaar eerder met eigen ogen gezien toen het paleis van Denpasar (de hoofdstad van het rijkje Badung) op 20 september 1906 werd ingenomen nadat de vorst eveneens in een puputan zelfmoord had gepleegd. Hij had toen zelf weinig kunnen verzamelen omdat de buit toebehoorde aan de Nederlandse regering, maar hij zag wel dat Baliërs onder de ogen van de legerleiding vele kunstschatten uit het paleis weghaalden. Hetzelfde zou dus gebeurd kunnen zijn met het ivoren doosje, alvorens het 17 jaar later aan kunstkenner Nieuwenkamp werd verkocht. Het is echter evenzeer mogelijk, dat het verhaal dat het in bezit was geweest van de Dewa Agung was verzonnen door de verkoper om de waarde van het voorwerp te verhogen. Vast staat echter wel dat het kostbare materiaal en het verfijnde vakmanschap van het beeldhouwwerk van dit zeldzame stuk een paleis waardig zouden zijn geweest. Vooral het gebruik van ivoor is bijzonder, meestal werden van dit materiaal alleen kleinere krisgrepen gemaakt. ${ }^{8}$

\section{Het leeuwtje als offerdoos}

Hetzelfde geldt voor het andere gedeelte van de 'overlevering', dat het doosje gebruikt zou zijn geweest door de vorst om er gouden munten in te vervoeren bij offerrituelen in één van de tempels van de stad Klungkung, de centraal gelegen Pura Balé Agung. De gouden munten als offerande zijn misschien een mooi verkoopverhaal geweest, maar het is wel een feit dat de Balische vorstenhuizen voor de verovering door de Nederlanders over grote sommen geld beschikten. Bjj de beschrijving van de oorlogsbuit na de oorlogen in Lombok, Badung en Klungkung werd steeds gesproken over duizenden gouden en zilveren munten, naast juwelen en andere kostbaarheden. Volgens ooggetuigen bij de puputan Badung strooiden vrouwen uit het paleis van Denpasar handenvol gouden munten voor de voeten van de soldaten, als een betaling om gedood te worden. Maar of er nu in het doosje gouden munten als offer werden vervoerd of niet, dozen in de vorm van een dier worden nog steeds op Bali gebruikt bij offerrituelen voor de goden. Dit zag ik onlangs nog bevestigd tijdens een kort bezoek aan Sanur, Zuid-Bali. Op 12 mei was het wegens volle maan tempelfeest in Pura Segara, aan het strand in Sanur. De tempel was prachtig versierd, want de goden van de tempel waren op bezoek, tijdelijk neergedaald in kleine, gouden beeldjes, arca. Deze stonden in een hoog, open paviljoen, vastgemaakt op de doos waarin zij de overige dagen van het jaar worden bewaard, en die nu was versierd met gekleurde doeken en veel bloemen. Ernaast, wat lager, bevond zich een rode, gevleugelde leeuw met bolle ogen en scherpe slagtanden, een roze sjaal om zijn nek en gouden bloemen op zijn hoofd (afb. 2). Op zijn rug droeg hij een banten canang, een klein offer. free access 

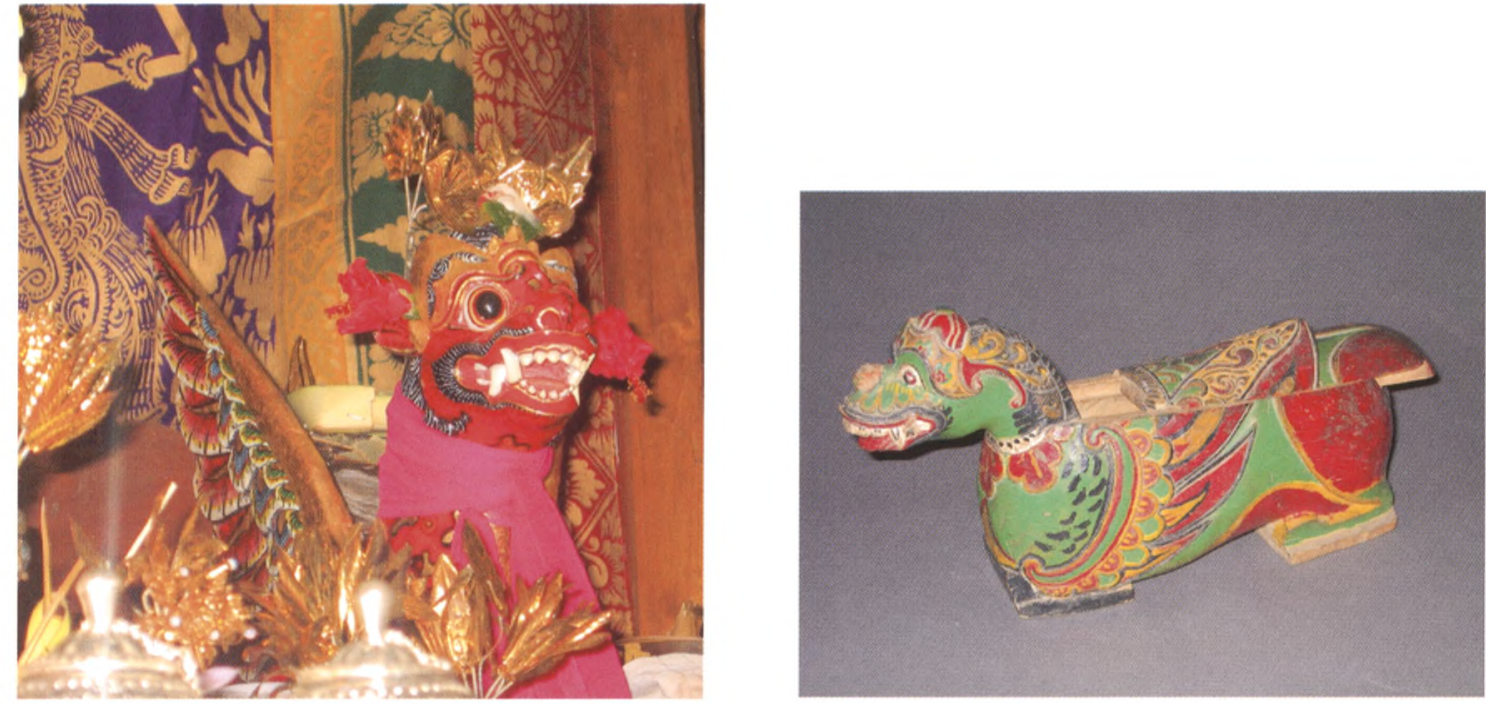

Afbeelding 2

Rode singa als zetel voor de goden, Pura Segara, Sanur, Bali, 12 mei 2006

Afbeelding 3 Penginang, houten sirihdoos in de vorm van een leeuw, uit Sewela, Lombok, verzameld door J.P. Kleiweg de Zwaan, vóór 1939. Rijksmuseum voor Volkenkunde, inv.nr. 2407. 405
Volgens de pamangku, tempelpriester, is deze leeuw een palinggih Ida Batara, een zetel van de goden. Hij hoort bij de beeldjes van de goden van deze tempel, die voor hem zorgen als een huisdier. Op zijn beurt zorgt het gevleugelde dier voor het vervoer van de goden en beschermt hij hen. De meeste tempels in Sanur hebben hun eigen rijdier voor de goden. In één van deze tempels, waar goden uit de andere tempels op bezoek kwamen omdat ook hier een tempelfeest werd gevierd, zag ik een gevleugeld hert, een gevleugelde stier en een dier met het lichaam van een vis, vleugels en de kop van een gans. $\mathrm{Zij}$ waren allemaal mooi versierd en droegen kleine offers op de rug, o.a. banten canang. Door sommige aanwezigen in deze tempel werden de dieren pacanangan genoemd.

Het woord canang betekent zowel sirihpruim, als klein offer waarvan de sirihpruim het belangrijkste bestanddeel vormt. Het aanbieden van de sirihpruim, een stimulerend middel, werd vooral vroeger op Bali (en in andere delen van Indonesië) beschouwd als teken van gastvrijheid en bevestiging van relaties, vooral in rituele context. De sirihpruim bestaat uit het blad van de sirihplant (Piper bitle), de noot van de pinangpalm (Areca catechu) en wat kalk. Hieraan kunnen worden toegevoegd wat tabak en gambir, een plantenextract (Uncaria gambir).

Een sirihdoos, met verschillende vakjes voor de ingrediënten van de sirihpruim, wordt op Bali, naast andere termen, een pacanangan genoemd, in het Indonesisch is dit penginangan of kinangan. In het Rijksmuseum voor Volkenkunde bevindt zich een beschilderde houten sirihdoos in de vorm van een gekroonde leeuw (inv. 2407-405) die volgens verzamelaar J.P. Kleiweg de Zwaan in Lombok penginang heet, de Sasak equivalent van het Balische pacanangan. Deze doos heeft een schuifdeksel in de rug, en de holle ruimte hieronder is in twee vakjes verdeeld, die waarschijnlijk de afzonderlijke ingrediënten van de sirihpruim konden bevatten, maar misschien ook de sirihpruim zelf (afb. 3 ). ${ }^{9}$

De dieren die op Bali een rol spelen bij tempelrituelen en soms pacanangan worden genoemd hebben echter meer te maken met de canang als offer dan met de losse ingrediënten van de sirihpruim. De banten canang is een van de meest voorkomende vormen van offers op Bali, het enige eiland in Indonesiëcess 
Afbeelding 6a (links) Beeld van een gevleugelde singa, met godenbeeldjes op de rug, verzameld op Bali door J.P. Kleiweg de Zwaan, vóór 1939. Rijksmuseum voor Volkenkunde, inv.nr. 2407-1

\section{Afbeelding $6 \mathrm{~b}$} Godenbeeldje gedragen op de rug van een tijger, Padang Calak, Bali, 18 maart 1977. Foto: David Stuart-Fox geplaatst (afb. 6b). En soms wordt het dier zelf beschouwd als vertegenwoordiger van een godheid, als beeld waarin goddelijke kracht tijdelijk plaats kan nemen. In Kerambitan, West-Bali, worden dergelijke dozen die in processies met de goden worden meegedragen, ampilan genoemd. ${ }^{15}$ Hier worden de dozen, als zij in functie zijn, gevuld met allerlei ingrediënten die zich ook in offers bevinden, een soort versterking van de spirituele inhoud die zij dragen. Als dragers van de goden is de functie van de dierendozen vergelijkbaar met die van andere dieren die als dragers fungeren. In de hindoeïstische mythologie, en ook in de Balische varianten hiervan, hebben de belangrijkste goden hun vaste rijdieren, wahana. Bekende voorbeelden zijn uiteraard de stier Nandi voor Shiva, de arend Garuda voor Vishnu en de gans Angsa voor Brahma. Terwijl deze dieren vooral zorgen voor transport, het vervoer van hun goddelijke meesters, zijn er ook dieren die in hun functie van drager vooral ondersteunend zijn en zorgen voor stabiliteit. Zo torst de schildpad Bedawangnala maar liefst de hele kosmos op zijn rug. Verder kent de rituele kunst van Bali nog een heel scala aan gevleugelde dieren die vaak een combinatie vertonen van allerlei karakteristieken van verschillende dieren, maar die niet direct een mythische achtergrond hebben. ${ }^{16}$

Op tal van manieren hebben dieren als dragers een plaats in de rituele kunst van Bali. De godenbeeldjes die worden vervoerd op de rijdieren, worden op hun rug gedragen, zoals ook de goden in de mythische verhalen op de rug worden vervoerd. Tijdens crematierituelen wordt het lichaam van een overledene verbrand in een patulangan, sarcofaag in de vorm van een dier, waardoor de ziel wordt bevrijd. Hierbij heeft het dier dus ook een dragende functie, echter niet op de rug, maar in de buik. Niets voor niets zijn de beide dierendozen uit het Museum für Völkerkunde te Berlijn, die verzameld zijn door C.M. Pleyte in 1901, geregistreerd als modellen van crematie-sarcofagen, en niet als offerdozen. Hierbij is het frappant dat de houten doos met inventarisnummer IC 31825 wat betreft de vorm sprekend lijkt op het ivoren leeuwtje, met als enige verschil het materiaal (afb.7). Een familie die ik op Bali goed ken, bezit ook een houten leeuw als doos of drager. Hierin bevindt zich de prasasti van de familie, een tekst op lontarblad
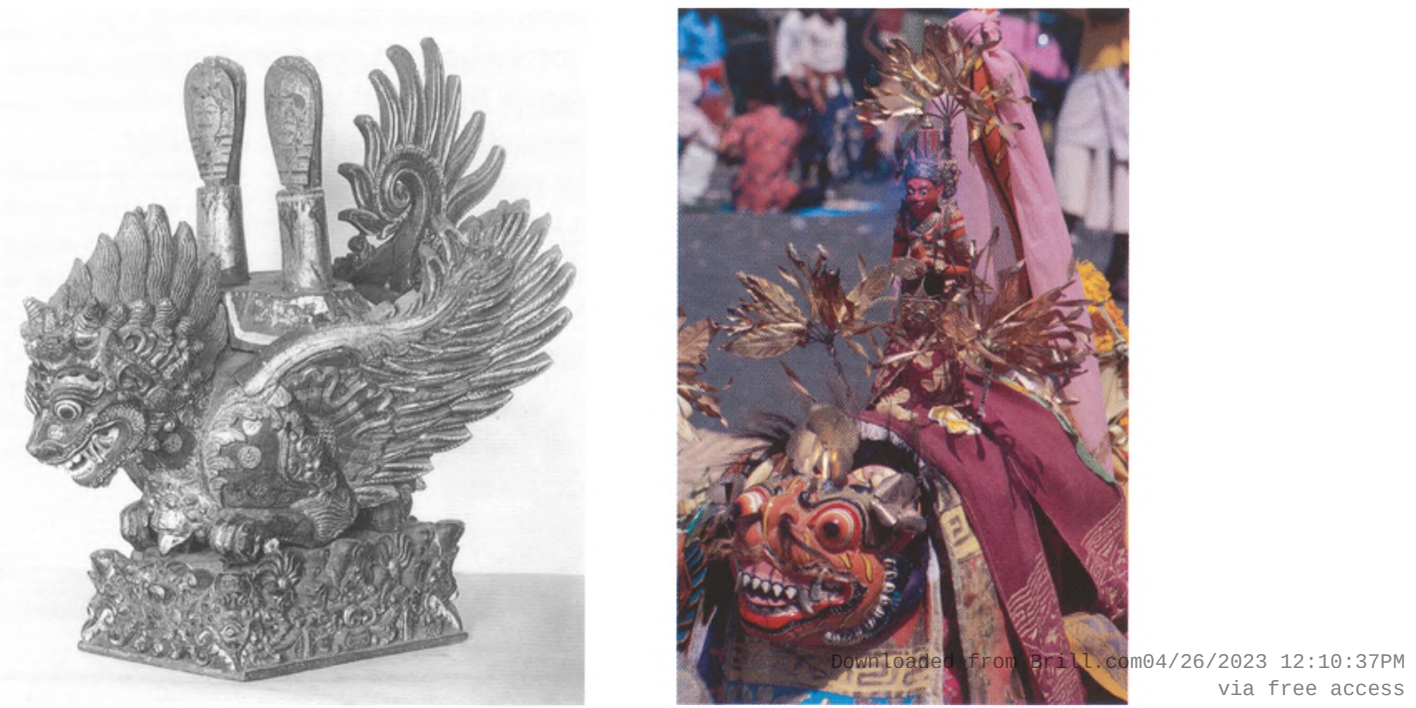


\section{Afbeelding 7}

Houten doos in de vorm van een gevleugelde

leeuw, in 1901

verzameld op Bali door

C.M. Pleyte. Museum fur Volkerkunde, Berlijn, inv.nr. IC 31825

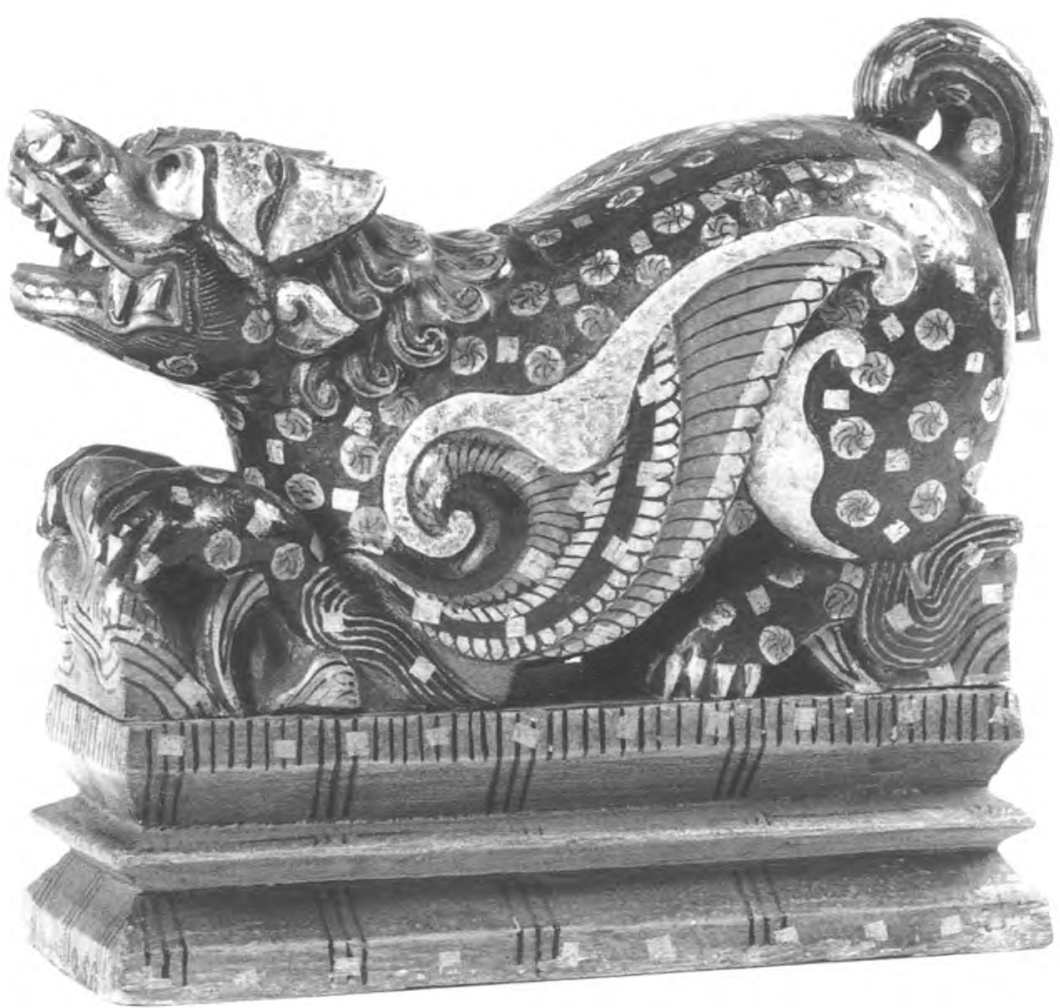

waarin staat dat de familie uiteindelijk afstamt van het vorstenhuis van Klungkung. Daarom wordt deze singa tegelijkertijd beschouwd als een zetel voor de vergoddelijkte voorouders.

Zeer interessant in de collectie van het Museum Nasional Indonesia in Jakarta is een drietal zilveren dieren, een gekroonde slang, een vogel en een kleine eend, alle met een deksel in de rug. Zij behoorden tot de rijkssieraden van het sultanaat Banjarmasin in Kalimantan, die in 1865 door het Nederlandse gouvernement werden geconfisqueerd en in het Museum van het Bataviaasch Genootschap (het tegenwoordige MNI) werden geplaatst. Zij lijken veel op de regalia, upacara, van het Sultanaat Yogyakarta. Tot deze upacara behoren vijf gouden dieren (overigens geen leeuw), het merendeel met een deksel in de rug, die ieder een aspect van het karakter van de Sultan als vertegenwoordiger van het goddelijke gezag op aarde representeren. Deze pusaka of heilige erfgoederen zijn afkomstig van de vorstelijke voorouders. ${ }^{17}$

Al deze dieren dragen dus, op hun rug of in hun buik of alleen symbolisch, iets dat in contact staat met de goddelijke, hogere wereld. Als rijdier, of mediator, kunnen zij een verbinding leggen met deze wereld, en ook, tijdens rituelen, het goddelijke zelf vertegenwoordigen.

\section{De 'singa'}

De leeuw, de vorm van het ivoren doosje, wordt op Bali singa genoemd. De singa heeft vaak vleugels, maar niet altijd. Hij kan in allerlei houdingen worden afgebeeld: staand met vier poten op de grond, op de achterpoten met de voorpoten opgeheven, zittend op de achterpoten met beide voorpoten gestrekt, en, zoals het geval is bij het ivoren leeuwtje, half liggend, met dee access 

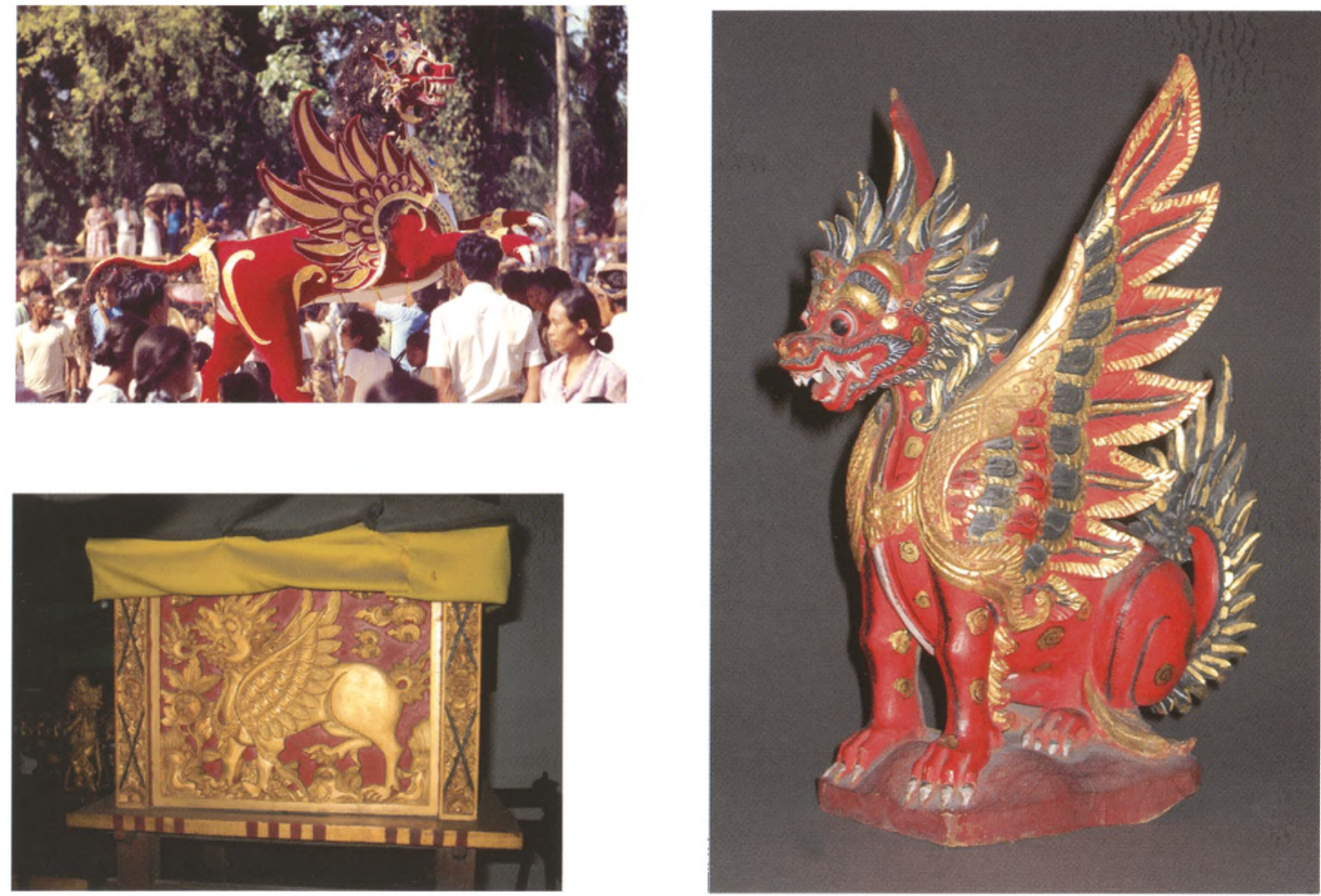

Afbeelding 8 (boven) Singa als sarcofaag, patulangan, voor de tweede crematie van Rudolf Bonnet, Ubud, Bali, 31 januari 1979

Afbeelding 9 (rechts) Gevleugelde leeuwfiguren als decoratief beeld. Rijksmuseum voor Volkenkunde, verzameld vóór 1899, inv.nr. 1216-7,

Afbeelding 10 (onder) Houten draagstoel met vergulde afbeelding van een gevleugelde leeuw, in 1916 verzameld door H.J.E.F. Schwartz in Karangasem, Bali. Museum Nasional Indonesia, inv.nr. 17853 buik bijna op de grond en met een gekrulde staart, de kop verwachtingsvol omhoog gericht met de oren naar achteren en de poten zodanig gebogen dat hij zo lijkt te kunnen wegspringen. Deze suggestie wordt versterkt door het feit dat het achterste deel van zijn rug is opgericht boven de hoogte van de kop. De voorpoten van dit leeuwtje rusten op een paar rotsmotieven. Net als de meeste monsterkoppen heeft de kop van de singa scherpe, uitstekende slagtanden, bolle, opengesperde ogen met wenkbrauwen die uitlopen in een soort hoorns, en een geopende bek. Hij heeft lange, krullende manen die zijn hele rug bedekken, en zelfs zijn vleugels lijken haarkrullen te bevatten. Net als andere dieren in de rituele kunst van Bali heeft de singa vooral een dragende functie. Hij komt vooral voor als palinggih (zetel) van godenbeeldjes en als patulangan (sarcofaag) bij crematies (afb. 8). Hij heeft dan een rode kleur en traditioneel vervoert de singa hierbij het lichaam van iemand van de Wesia-kaste, dat wil zeggen de derde kaste, van adellijke personen die van lagere afkomst zijn dan de tweede kaste van de Ksatria's. Het meest frequent is het gebruik van de singa in de architectuur als sokkel van pilaren, sendi ${ }^{18}$ of van de verticale stijl die rust op de horizontale nokbalk van een dak. ${ }^{19}$ De (gevleugelde) leeuw is dus op Bali behalve transporterend ook dragend in de zin van ondersteunend, stabiliserend. Maar hij kan ook dienen als stop van een bamboe koker of van een waterkan of -fles, ${ }^{20}$ of als decoratief beeld (afb. 9), of afgebeeld zijn op tempelmuren of -poorten en op paleisdeuren en draagstoelen (afb. 10). ${ }^{21}$

Hoewel de naam singa is afgeleid van het Sanskrit singha dat leeuw betekent, en één van de grotere steden op Bali, Singaraja, naar de leeuw is genoemd, is de singa op Bali niet het rijdier van de godin Durga,zoals datmin/Lndia wel het $37 \mathrm{PM}$ geval is. ${ }^{22} \mathrm{Hij}$ lijkt hier een meer zelfstandige rol te spelen. Opvallend is de access 

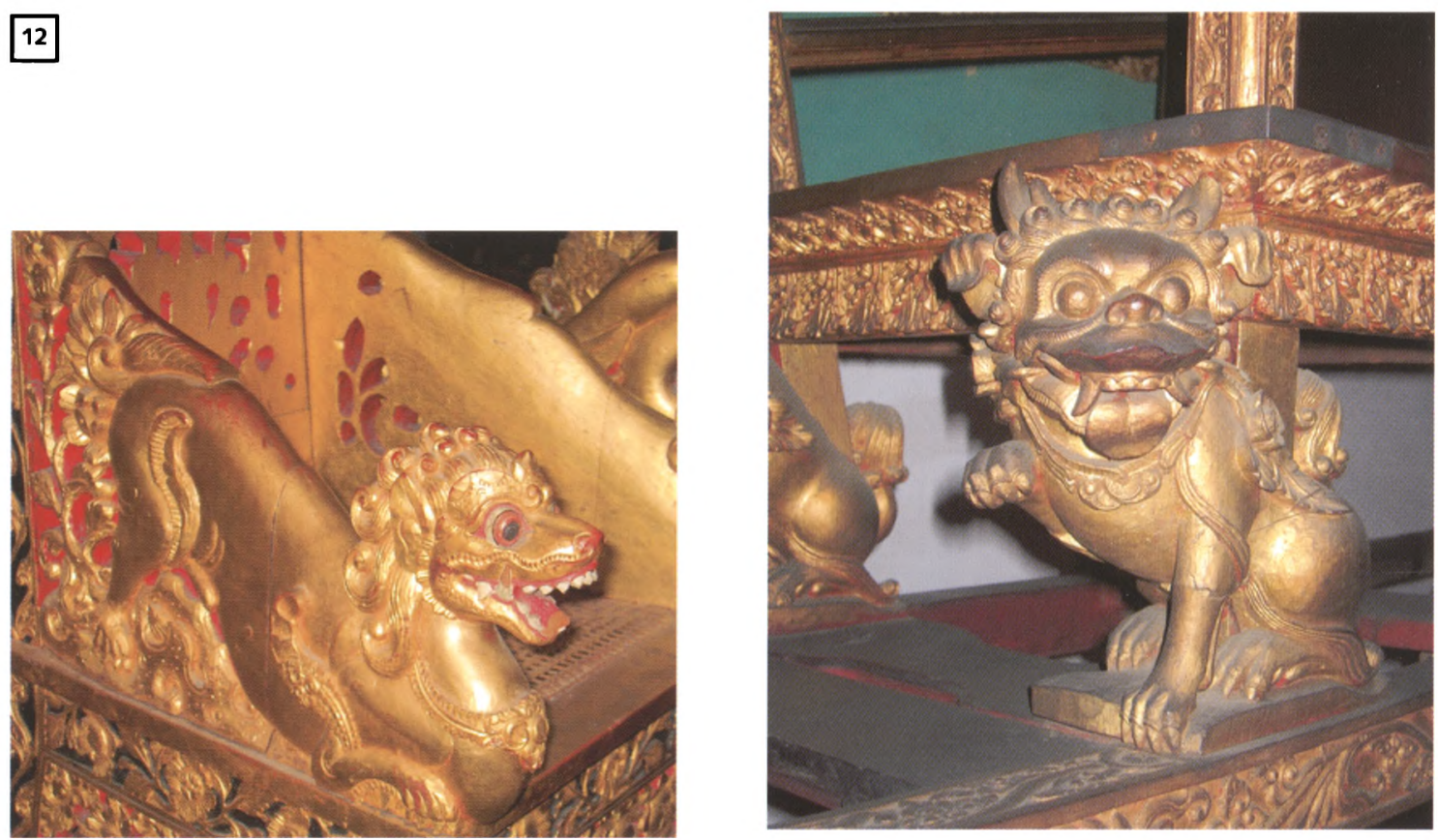

Afbeelding 11 (links) Vergulde houten stoel uit het gerechtshof van Klungkung, met armleuningen in de vorm van een leeuw. Rijksmuseum voor Volkenkunde, inv.nr. 2582-2

\section{Afbeelding 12}

Vergulde leeuw waarop de in 1905 gemaakte draagstoel rust van de vorst van Pamecutan, Denpasar, Bali. Buitgemaakt na de militaire expeditie tegen Badung, 20 september 1906. Museum Nasional Indonesia, inv.nr. 13180. overeenkomst tussen de vorm van het gezicht van sommige singa, waaronder het leeuwtje van de doos, en de monsterkoppen die in hindoe-javaanse tempelcomplexen boven ingangen zijn aangebracht. Behalve de bolle ogen en slagtanden zijn vooral de hoorntjes als verlengstuk van de wenkbrauwen een kenmerk van de monsterkoppen van bijvoorbeeld Candi Singasari in OostJava. ${ }^{23}$

Behalve dit mogelijke verband met het hindoe-boeddhistische verleden, lijkt het er ook op, dat de vorm van de Balinese singa is beïnvloed door die van de Chinese leeuw. De vorm van het ivoren leeuwtje lijkt vooral sterk op die van Chinese dakdecoraties. ${ }^{24} \mathrm{Al}$ eeuwenlang, eigenlijk al vanaf de prehistorie, bestonden er contacten tussen Bali en China, die vooral gebaseerd waren op handel. Ook de mythische, beschermende barong, een leeuw-achtige figuur die op Bali bij rituelen een rol speelt, is vermoedelijk afgeleid van de Chinese leeuwen die tijdens het Nieuwjaarsfeest op straat dansen om kwaad af te weren en geluk en voorspoed te brengen. ${ }^{25}$ Vooral in de tempel- en paleisarchitectuur heeft de Chinese invloed zijn sporen nagelaten. Nieuwenkamp zelf schreef over de hoofdpoort van het paleis van Klungkung (die na de puputan in 1908 is blijven staan): 'Zowel dit snijwerk als de vorm der deuren duidt sterk op Chineeschen invloed, en zijn zeker door Chineesche werklui vervaardigd.'26

Ook van de paleizen van Denpasar, Karangasem, Bangli en Mengwi is bekend dat er Chinese handwerkslieden aan hebben gewerkt, vanaf het eind van de $18^{\mathrm{c}}$ eeuw. ${ }^{27}$

In Azië, maar ook in Afrikaanse en Europese culturen is de leeuw, als koning der dieren, geassocieerd met de macht van de vorst. ${ }^{28}$ Zo bezit het Rijksmuseum voor Volkenkunde bijvoorbeeld een vergulde stoel uit Klungkung, die zou hebben toebehoord aan de Raad Kerta, het gerechtshof dat deel uitmaakte van het paleis. De armleuningen bestaan uit twee leeuwen, in 1 in : 37pM dezelfde houding afgebeeld als de ivoren leeuw (afb. 11). ${ }^{29}$ via free access 
In het Museum Nasional Indonesia in Jakarta zijn vier houten, vergulde leeuwen te zien als dragers van de draagstoel van de laatste vorst van Pamecutan, Badung (afb. 12). Gedragen in deze stoel (inv. nr. 13180) ging de vorst op 20 september 1906 de rituele zelfmoord van de vorstelijke familie, puputan, tegemoet. Nieuwenkamp heeft ook twee van dergelijke leeuwen kunnen verzamelen voor zijn privé-collectie. $Z$ ij zouden afkomstig zijn van de draagstoel van de laatste vorst van Denpasar, die eerder op die dag tijdens de puputan Badung was omgekomen. Misschien zijn deze ook door Chinese houtsnijders gemaakt, want Nieuwenkamp schreef hierover het volgende: 'Dit is geen Balische singa, doch een Chineesche leeuw, saé of singa Tjina. Deze bezit geen vleugels als de singa op de vorige plaat (de ivoren leeuw, FB); is bovendien kenbaar aan een rank met bladeren en bloemen, die het beest in den bek houdt.' 30

Hoe het ook zij, in ieder geval hebben we hier te maken met een vorstelijke leeuwendoos, in 1925 verzameld door kunstkenner W.O.J. Nieuwenkamp. Het prachtig gedecoreerde, ivoren exemplaar dat hij in Klungkung wist te bemachtigen is uniek, inderdaad 'een uiterst zeldzaam stuk, zooals er weinig op Bali te vinden zullen zijn'.

\section{Noten}

Alle foto's behalve afb. 1,6 en 7: Francine Brinkgreve

1. Zie ook: Pauline Lunsingh Scheurleer (red.), Asiatic Art in the Rijksmuseum, Amsterdam, Amsterdam, 1985, p. 189 en 'Tentoonstelling van de Vereeniging "Oost en West" van de verzameling W.O.J. Nieuwenkamp in het Stedelijk Museum te Amsterdam', Nederlandsch-Indië Oud en Nieuw XI (1926/1927), pp. 347-352.

2. Met dank aan: dhr. Cary Venselaar en dhr. J.F.K. Kits Nieuwenkamp voor het ter beschikking stellen van ongepubliceerd materiaal van W.O.J. Nieuwenkamp; aan het Rijksmuseum voor Volkenkunde in Leiden, het Museum Nasional Indonesia in Jakarta, het Museum Bali in Denpasar en het Museum für Völkerkunde in Berlijn voor het afbeelden van voorwerpen uit hun collecties; en aan dr Hedi Hinzler, drs Pauline Lunsingh Scheurleer en dr David Stuart-Fox voor aanvullingen en commentaar op een eerdere versie van dit artikel.

3. W.O.J. Nieuwenkamp, Bali en Lombok, Edam, 1906-1910, pp. I-VII.

4. W.O.J. Nieuwenkamp, Inlandse Kunst in Nederlandsch Oost Indië, deel II Beeldhouwkunst van Bali, 's-Gravenhage, 1928, p. 11, plaat 34.

5. W.O.J. Nieuwenkamp, Een florentijnsche villa, 's-Gravenhage, 1938, p. 44. In feite was dit een afbeelding van een van de vitrines van de tentoonstelling 'Indonesische Kunst, Sammlung Nieuwenkamp' in Westfalen, 1928 ('Recente tentoonstellingen van Indonesische kunst te Amsterdam, Parijs, Hagen en Munchen', NederlandschIndië Oud en Nieuw XIII (1928-1929), pp. 125 - 128).

6. W.O.J. Nieuwenkamp, Bali en Lombok, Edam, 1906-1910, p. 203.

7. Zie ook: Francine Brinkgreve, 'Vorsten van Bali en koloniaal gezag; collectievorming en politiek', in: Endang Sri Hardiati \& Pieter ter Keurs (red.), Indonesia, de ontdekking van het verleden, Amsterdam, 2005, pp. 122-146.

8. Bijvoorbeeld RMV inv. 214 -7, gepubliceerd in: Hans-Werner Hegemann, Schnitzkunst und Plastik aus Indonesien, Odenwald, 1977. Zie ook: J.A. Loubèr Jr., Been-, hoorn- en schildpadbewerking en het vlechtwerk in Nederlandsch-Indië, Amsterdam, 1916. De vorst van Gianyar bezit een rijk bewerkte olifantstand, zoals te zien is op p. 63 in: Leonard Lueras, Fire, a Balinese yourney of the soul, Gianyar, 1994.

9. Rijk bewerkte sirih stellen, waarbij alle doosjes en attributen die te maken hebben met de ingrediënten van de sirihpruim waren verzameld op een (yaak goudęn) 
ovalen schaal op een houten voetstuk, lelancang, behoorden tot de vaste attributen waarmee een vorst zich omringde. Soms hadden zij eigen namen en behoorden zij tot de familie-erfstukken, pusaka. Op de laatste bekende foto van de vorst van Klungkung, genomen kort voor de puputan in april 1908, zit naast hem op de grond Cokorda Putu Plodot met het sirih stel I Kawotan (Margaret J. Wiener, Visible and invisible realms: power, magic and colonial conquest in Bali, Chicago, 1995, p. 319). Tot de oorlogsbuit na de puputan Klungkung behoorden een paar prachtige lelancang (o.a. MNI 14830/ E 749) en andere onderdelen van een sirih stel, zoals kacip, mooi met goud ingelegde scharen om de noten van de pinangpalm mee klein te maken. Zie: Endang Sri Hardiati \& Pieter ter Keurs (eds.), Indonesia, de ontdekking van het verleden. Amsterdam, 2005, pp. 138-139.

10. Iedere dag en overal wordt op Bali geofferd aan goden, voorouders en demonen, om de relaties tussen de zichtbare (sekala) en onzichtbare (niskala) wereld in balans te houden. Er bestaan op Bali honderden verschillende soorten offers, waarvan de namen, vormen en samenstelling per regio en soms per dorp kunnen verschillen, maar de banten canang komt, als een van de basisoffers, overal voor. Het offer bestaat uit een klein bakje van palmblad, waarop wat voedsel in de vorm van rijst en kleine stukjes banaan en suikerriet en koekjes van rijstmeel zijn gelegd, met daar bovenop verschillende kleuren bloemen en de sirihpruim, waaraan dit offer zijn naam ontleent. Zie: F. Brinkgreve en D. Stuart-Fox, Offerings, the ritual art of Bali, Sanur, 1992.

11. Ny. I. Gst. Ag. Mas Putra, Upakara Yadnya, Denpasar, 1982, p. 19.

12. Museum Bali, Pameran patung singa koleksi Museum Bali, Denpasar, 1978. De inv.nrs. 195, 1084 en 2381 worden pacanangan singa genoemd.

13. Het MNI in Jakarta bezit een vergelijkbaar leeuwtje, inv. nr. 24068. A.N.J.Th. à Th. van der Hoop, 'De Ethnografische verzameling', Jaarboek VIII Koninklijk Bataviaasch Genootschap van Kunsten en Wetenschappen, Bandoeng, 1941, p. 185:

'Houtsnijwerk, voorstellende een gevleugelde leeuw met vlammende manen en staart; op den rug staan los twee kleine godenfiguren [...],in 1940 aangekocht uit den geliquideerden kunsthandel van de gebroeders Neuhaus te Sanoer, Zuid Bali.'

14. Vergelijk P.J. Zoetmulder, Old Javanese - English dictionary, 's-Gravenhage, 1982, p. 1319: 'patarana = (ceremonial) cushon or mat to sit on.'

15. Informatie van Hedi Hinzler. Het is op Bali een veel voorkomend verschijnsel, dat dezelfde voorwerpen in verschillende regio's een verschillende naam hebben. Vergelijk Th. Pigeaud, Javaans-Nederlands handwoordenboek, Groningen, Batavia, 1938, p. 8: 'ampilan = waardigheidstekenen (met iemand meegedragen).' In de Midden-Javaanse vorstenhuizen is dit de naam van staatsie- of vorstelijke waardigheidstekenen van de sultan, die in zijn nabijheid worden meegedragen. Zie J. Groneman, In den kedaton te Jogjakarta; oepatjara, ampilan en toneeldansen, Leiden, 1888, pp. 44-46 en K.P. Hadiwidjoyo, 'De Rijkssieraden van het Mangkoenagaransche vorstenhuis', Djawa, 1924, pp. 10-12.

16. Een voorbeeld is het prachtige gouden tabaksdoosje (eveneens uit het paleis van Klungkung) uit de collectie van het MNI (inv. 14837 / E 786) dat in de Nieuwe Kerk was te zien. Het lichaam was dat van een visje, het had de poten en vleugels van een vogel en als hoofd een afschrikwekkend monsterkopje met bolle ogen, scherpe uitstekende hoektanden en een uitgestoken tong. Zie Endang Sri Hardiati \& Pieter ter Keurs (red.), Indonesia, de ontdekking van het verleden, p. 138.

17. J. Groneman, In den kedaton te Jogjakarta; oepatjara, ampilan en toneeldansen, Leiden, 1888 , pp. $40-41$.

De Midden- Javaanse vorstenhuizen, de Balische koninkrijken en het sultanaat Banjarmasin hebben een gemeenschappelijke historische achtergrond in het $14^{\mathrm{e}}$ eeuwse, hindoe-boeddhistische rijk Majapahit.

18. Arne \& Eva Eggebrecht, Versunkene Königreiche Indonesiens, Mainz, 1995,

fig. 249; Made Wijaya, Architecture of Bali: a sourcebook of traditional and modern forms, Londen, 2003.

19. A.N.J.Th. à Th. van der Hoop, Indonesische siermotieven, Batavia 1949, $\mathrm{Pp}_{23} 154: 10: 37 \mathrm{PM}$ 
155: Helen Ibbitson Jessup, Court arts of Indonesia, New York, 1990, p. 104.

20. Bijvoorbeeld RMV inv.nrs. 214-6 en 3557-24. Zie ook: Tibor Bodrogi, Kunst van Indonesië, Den Haag, 1971, fig. 147.

21. Bijvoorbeeld: MNI inv.nr. 17853, H.J.E.F. Schwartz, Gids voor den bezoeker van de ethnographische verzameling. Zaal B Bali en Lombok, plaat III; RMV inv.nr. 1586-32, H.H. Juynboll, Catalogus van 's Rijks Ethnographisch Museum. Deel VII Bali en Lombok, plaat IX; RMV inv.nr. 1586-31, Endang Sri Hardiati \& Pieter ter Keurs (red.), Indonesia, de ontdekking van het verleden, Amsterdam, 2005, p. 132.

22. Heinrich Zimmer, Myths and symbols in Indian art and civilization, New York, 1962.

23. Pauline Lunsingh Scheurleer wees mij op dit mogelijke verband. Zie ook E.B. Vogler, De monsterkop uit het omlijstingsornament van tempeldoorgangen en -nissen in de Hindoe-Javaanse bouwkunst, Leiden, 1949, p. 38: 'dat [...] de monsterkop van het omlijstingsornament, voor zover deze samengaat met een makara-boog, steeds een echte singha-kop is [...]'

24. Katherine M. Ball, Animal motifs in Asian art, New York, 2004, pp. 64-65.

25. Ong Hean-Tatt, Chinese animal symbolisms, Malaysia, 1993, pp. 235-40; Wolfram Eberhard, Dictionary of Chinese symbols, Singapore, 1983, pp. 164-165.

26. W.O.J. Nieuwenkamp, Bouwkunst en beeldhouwkunst van Bali, 's-Gravenhage, 1947, p. 13.

27. Informatie van Hedi Hinzler.

28. Margaret \& James Stutley, A dictionary of Hinduism, Londen, 1977, p. 277.

29. RMV inv.nr. 2582-1. Er is ook een andere stoel, RMV inv.nr. 2582-2, die gekroonde slangen als armleuningen heeft.

30. W.O.J. Nieuwenkamp, Bouwkunst en beeldhouwkunst van Bali, 's-Gravenhage, 1947 , p. 30 . Sae betekent leeuw in het zuid Chinees. Het takje in zijn bek heeft waarschijnlijk te maken met de leeuwendans tijdens het Nieuwjaarsfeest (informatie van Hedi Hinzler). 


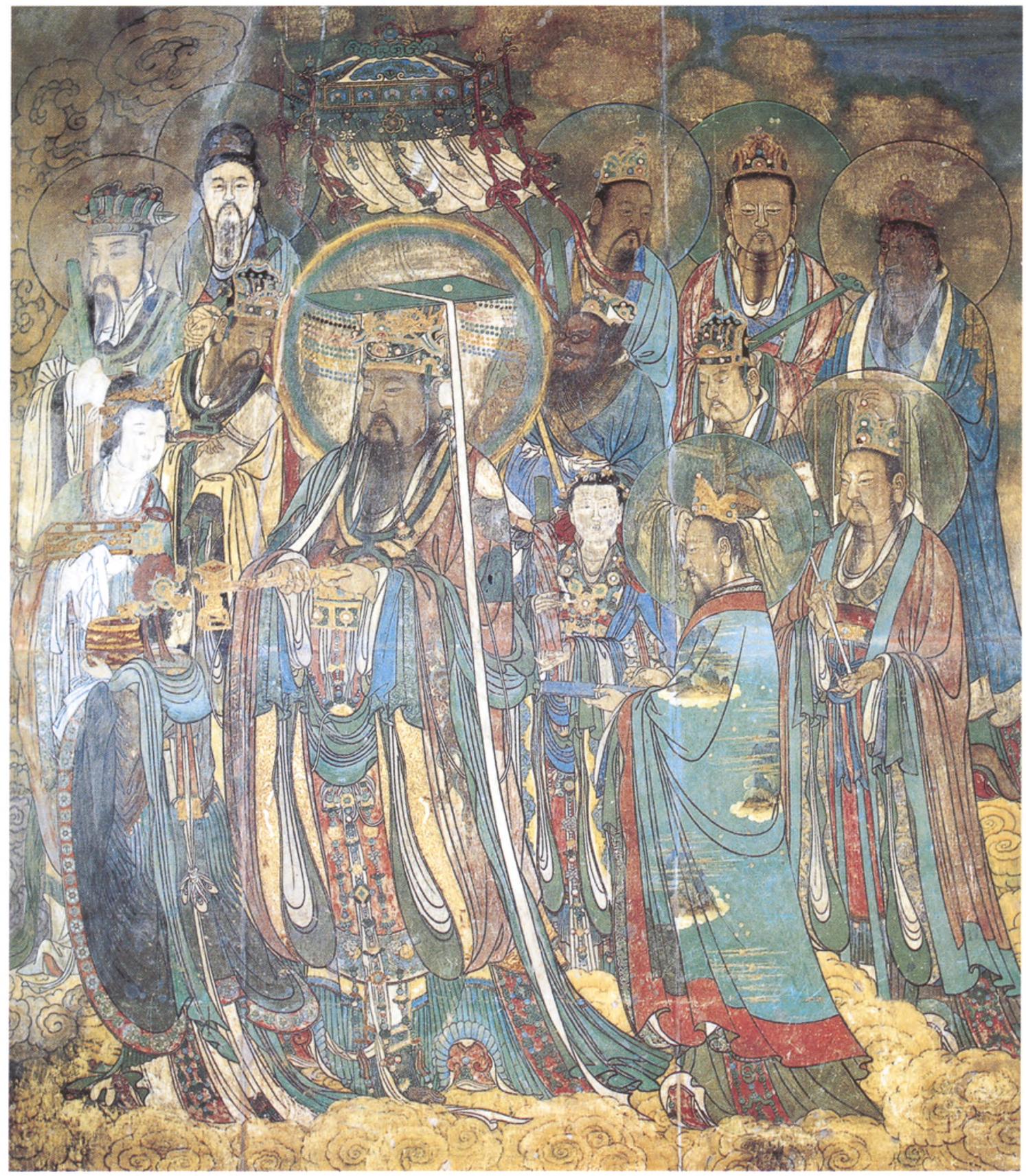

Afbeelding 3

God van de Zuidelijke Poolster en vijf daoistische priesters. Oostmuur van

centrale niche, Yongle gong, Ruicheng,

Shanxi, gedateerd 1325 .

lin Weinuo, Zhongguo diantang bihua

quanji: Yuandai daoguan. Vol. 3.

Taiyuan, 1997, p. 18 